\title{
Correspondence
}

\author{
Letters to the Editor should not exceed 500 words.
}

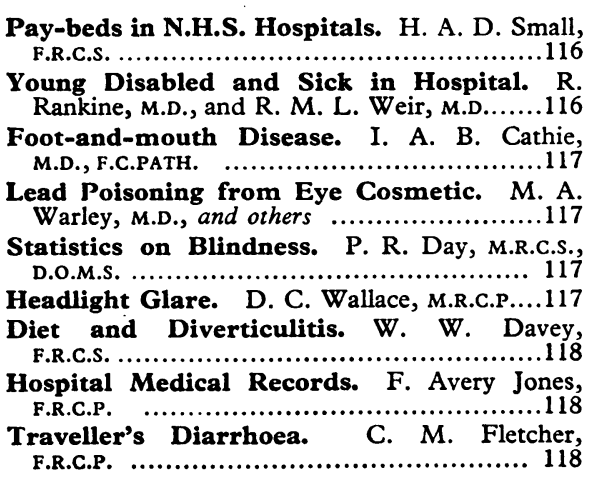

Human Tetanus Antitoxin. A. G. Freeman, M.D.; W. H. Crichton, D.P.H..............119 Improving the Psychiatric Services. R. S Ferguson, M.D., D.P.M. .....................119 Psychotropic Drugs. H. M. Flanagan, D.P.M. .....................................119

Requests for Abortion. W. T. Mackie, M.B. ........................................120 Congenital Dislocation of the Hip. R. Owen, F.R.C.s. ......................................120

British Association of Manipulative Medicine. J. H. Ebbetts, M.R.C.S. ......................120 Bethanidine in Hypertension. A. W. D. Leishman, F.R.C.P., and others................120

Cause of Death. V. H. A. Black, D.P.M., and others; A. Wendy Wright, M.B.; I. D. Riley, others; A. Wendy Wright, M.B.; I. D. Riley,
F.R.C.P.GLASG. ................................120
Fibrin Degradation Products. J. D. Cash, M.R.C.P.ED., and others.......

Haemorrhagic Necrosis of the Intestine. A. G. Bhagwat, M.D.PATH...................121 Sarcoid Myopathy. J. G. Scadding, F.R.C.P..................................121

Australia Next? A. Clements, M.B..........121 Return to Britain. P. W. Grant, L.R.C.P....122 Administrative Delays over Health Centre. R. F. Wyatt, M.B., and others...............122 Managing the Hospitals. H. Weisl F.R.C.S. ..........................................122 Reimbursement of Rent and Rates. A. P

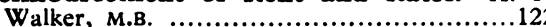

B.M.J. Cover. A. T. Spoor, M.R.C.S.; M. J. Jameson, M.B.; D. J. Davies, M.R.C.s.; Squadron
SIR,-Regional hospital services committees accepted in advance the recent package deal with the Minister covering the provision and use of pay-beds. They knew that these were still accepted as part of the N.H.S. hospital service ; they knew that demand was increasing, and they foresaw that rationalization might lead to contracture or closure of small units at incompletely equipped hospitals they expected a reasonable provision at major centres at present lacking. It is difficult for a regional hospital doctor to understand what the deal has produced.

I am not especially referring to the percentage cut in the numbers of pay-beds, though I think that in the face of the demand this is unwise and irrational. We can see that this decision is emotional and doctrinaire and must be argued elsewhere ; but regional hospitals carry the majority of the work load and employ a majority of consultants, and it is difficult for them to see how the profession's negotiators could have accepted such a savage discrimination in favour of teaching hospitals and against the regional hospitals struggling to gain an esteem which equals the quality of their work (I am speaking especially of the North-west Metropolitan Region) Peripheral patients are also members of one or other of the flourishing insurance schemes, and they also include some fortunate or prudent enough to be able to afford a personal service and the advantage of a pay-bed which the N.H.S. has quite rightly decided to provide; and occasionally the reputation of a regional consultant stands high enough for him to attract a patient from outside his area or even his country.

In the North-west Metropolitan Region, in which I serve, the cut in the pay-beds at teaching hospitals is from 487 to 467 (4.1\%) - the small reduction being made in secondary units-mostly recent additions to their complement. There is not one fewer in the major purpose-built units. In the regional hospitals it is from 303 to $241(20 \%)$. The effect of this will be to demonstrate most practically to patients that this is a form of treat- ment which cannot be equally well obtained from their regional hospital, however willing consultants may be to provide the service and however much the patient may desire it.

It was suggested that reductions would be made in poorly used and less efficient units, and that an improvement might be expected in the more efficient regional hospitals. This is not the case. In the North-west Metropolitan Region there are only seven nonteaching hospitals with more than 10 beds. In four of them the occupancy is well over $100 \%$ of the proposed new figure, while the standing of the hospitals will speak convincingly against any suspicion of inefficiency.

One hears it said that the Minister's first word to his hospital specialists on this matter is also his last. One hopes that this is not so ; and one hopes that if for doctrinaire reasons a percentage cut has been irrevocably decided the teaching hospitals will agree to have the cut applied equally with their less fortunate associates. A cut of $10 \%$ in the quite substantial number of pay-beds administered by the teaching hospitals would, if restored to the regional hospitals, allow the cut to be reduced from $20 \%$ to $10 \%$ - still bad and unrelated to legitimate demand but better and less discouraging than the proposed figure.-I am, etc.,

London $W 1$.

Alan Small.

\section{Young Disabled and Sick in Hospital}

SIR,-We would be grateful for the courtesy of your columns in order to amplify a sentence in your leading article on the young disabled and sick in hospital ( 9 December, p. 565), which we feel may perhaps be misunderstood.

In your very generous reference to our survey in Fife" you state that "the authors ... suggest that unsatisfactory housing conditions were of little importance. ...." Our survey did in fact show that unsatisfactory housing played no significant part in the lives of these patients, the great majority of whom enjoyed the advantages of a modern home. As we pointed out in our concluding chapter, however, this finding, while valid for the county of Fife, may not apply e!sewhere, and adverse housing conditions such as still exist in many of our older urban areas may exert a considerable influence on the demand for hospital or other accommodation for the chronically sick or disabied. We would not wish it to be thought that housing conditions have, in general, little impact on the lives of those who are being cared for at home.

We entirely support your conclusion that separate small hospital units should be provided for these patients, preferably within general hospitals in which all the resources in terms of nursing and medical auxiliary staff can be mobilized and in which specialist services are available at need, and where, at the same time, the group activities and social interests, which are so essential to these patients, can be properly organized. We are unable to agree with the recommendation of the Working Party on the Organization of Medical Work in the Hospital Service in Scotland ${ }^{2}$ that younger chronic sick patients should be "dispersed by specialty" under the consultant primarily responsible for them. We consider this proposal to be based on a misconception of the needs of these long-term patients.

We would add that the report on our survey, though not published, has been reproduced for us by the South-eastern Regional Hospital Board (Scotland), and a copy can be supplied to any reader who is interested in the problems of this hitherto neglected group of patients. - We are, etc.

ROBERT RANKINE.

ROBERT M. L. WEIR.

Victoria Hospital, Kirkcaldy, Scotland.

\section{REFERENCES}

1 Rankine, R., and Weir. R. M. L.. An Enquiry into the Incidence of Chronic lliness and Disability in the Young and Middle-aged. 1967. Organization of Medicul Work in the Hospital Organization of Medicul Work in the Hospital
Service in Scotland, 1967 H.M.S.O. See also Service in Scotland, 1967
Brit. med. F., 1967, 4, 291. 